Administrative Issues Journal: Connecting Education, Practice, and Research, Summer 2017, Vol. 7, No. 1: 5-18. DOI: 10.5929/2017.7.1.3

\title{
Color-blind racial attitudes: Microaggressions in the context of racism and White privilege
}

\author{
Jared F. Edwards, Ph.D. \\ Southwestern Oklahoma State University
}

\begin{abstract}
Interest in institutional racism, White privilege, and microaggressions appears to be growing. We are living in times when the impact of race and racism are debated-when even the existence of racism is debated along with the appropriateness of examining the worst parts of U.S. history. This special-issue invited article includes a brief examination of historical information and current context in which racism and microaggressions exist, leading to their connections to Color-Blind Racial Attitudes (COBRAs). Reviewed research on COBRAs addresses teacher training, educational practices, experiences on college campuses, and organizational management.
\end{abstract}

Keywords: institutional racism, White privilege, microaggressions, Color-Blind Racial Attitudes

Author note: I would like to thank the other AlJ Editorial Board members for making this special issue possible and for allowing me to contribute to it with this invited article. I would also like to express my gratitude to the authors of the articles in this issue and their willingness to tackle these difficult and personal subjects. Finally, I want to thank Dr. Jorie Edwards for her insight and feedback on this article.

A $\mathrm{s}$ an introduction to $A I J$ 's special section on microaggressions, I have been given the opportunity to provide some context and basic definitions. The most fundamental question related to any topic can be reduced to this: Is this topic worth discussing or exploring? More plainly: Does it matter?

As obvious as the answer may seem, it has been met with debate. Sue et al. (2008) directly addressed the challenges that they have received to their work on microaggressions. In my own experience discussing and teaching the concept of microaggressions and other topics related to diversity, I have been asked if, and in some cases, have been told that, issues related to prejudice, including racism, sexism, heterosexism, gender bias, and ethnocentrism would go away if we would just stop talking about them and drawing attention to them. This idea holds two implications. First, it suggests a seductive idea: there is an easy solution to all types of strife in our society; just ignore them. Second, and more problematic for multicultural research, education, and social activism, we are being told that our work is not part of the solution, but rather the source of the problem.

EDWARDS / DOI: 10.5929/2017.7.1.3 
I intend to make the case for addressing questions of diversity, including the topics of microaggressions and institutional racism as our journal and the following authors have chosen to do, through active exploration instead of through avoidance and denial. I will begin with examination of the social context in which prejudice, discrimination, and microaggressions occur. Then I will provide a brief overview of institutional racism (Neville, Worthington, \& Spanierman, 2001); White privilege (D'Andrea \& Daniels, 2001), which is a both a source and a result of institutional racism; and microaggressions (Sue \& Sue, 2013), which are a source and result of institutional racism and White privilege. Finally, I will focus on Color-Blind Racial Attitudes (CoBRAs; Neville et al., 2000) and Color Blind Racial Ideology (Neville et al., 2013), which are a specific type of microaggression and a perpetuating factor in other types of microaggressions (Sue \& Sue, 2013, p. 157).

\section{Social \& Cultural Context}

The context in which racism, prejudice, and discrimination exist in the United States is complex. Our history is a one of promise and triumph, but also failed opportunities. It is beyond the scope of this, or any, article to fully address the history of prejudice and discrimination in the United States, but some exploration of context seems appropriate. My intent is not to negate or deny the growth and progress the U.S. has accomplished, but to recognize that concerns and anxieties expressed by members of racial and ethnic minority groups are based in recent history and current issues, not just the distant past.

How U.S. history should be presented is, in itself, a hotly debated topic. Some argue that probing the following information is unpatriotic or anti-American, with multiple states challenging the content of AP history courses for focusing on negative components of U.S. history (Stefanoni, 2015). However, it is my belief that we can be proud of our accomplishments while acknowledging and challenging our shortfalls. The historical and current issues cited below are drawn from a combination of academic text books, peer reviewed journal articles, and popular press/news media (especially for recent news items in 2016 and 2017). For many of the following issues, one or two articles from dozens of options are presented as examples of what is available.

\section{Historical Context}

Some parts of U.S. history are sufficiently well-known to be considered common knowledge without denying the importance of their impact on our collective history or on the people who experienced them. The history of slavery and segregation based on race (especially for African Americans) falls into this category. Other examples of discrimination and oppression may be less well-known. Examples of racial discrimination are woven throughout the development of U.S. culture. There are many possible examples of injustice and oppression that are not included here. This is not meant to devalue or negate those experiences.

In addition to slavery and forced relocation of native tribal groups (including but not limited to the Trail of Tears; Sue \& Sue, 2013, p. 384), there have been attempts to control what groups of people have been allowed to immigrate to the United States (Allerfeldt, 2003; Calavita, 2006; Faragher, Buhle, Czitrom, \&

EDWARDS / DOI: 10.5929/2017.7.1.3 
Armitage, 2012, pp. 609-610), attempts to force assimilation of non-European populations within the United States (Dawson, 2012; Sue \& Sue, 2013, p. 384), and attempts to limit the reproduction of nonEuropeans (Ellis \& Abrams, 2009, pp. 388-395).

Among policies based on racial and ethnic discrimination were restrictions focusing on Chinese immigrants, with limits on Japanese immigrants added later (Allerfeldt, 2003; Calavita, 2006). These policies represented an effort to keep Asian traditions and values from gaining a significant influence on the development of culture in the American West. Also, in what may be one of the more underacknowledged cases of discrimination based on country of origin, during World War II, Japanese Americans living on the west coast were forced to relocate to internment camps to prevent them from supporting a much-feared Japanese invasion of the west coast (Faragher et al., 2012, pp. 662-663; Wollenberg, 2012). The Japanese internment camps began operating in 1942, with the last camp closing in 1946 (Muyskens \& Steckelberg, 2017).

Discrimination against American Indians illustrates another deep-seated issue in the U.S. history of diversity. This was the forced assimilation that was an explicit attempt to eradicate a culture's traditions and values, if not its members. Most students of U.S. history are aware of tribes forced to relocate from Eastern and Southern States to territory in the Southwest (Sue \& Sue, 2013, p. 384). Fewer may be aware of the Indian Schools which functioned as boarding schools for the openly expressed intent of separating children from their tribe and family in order to prevent transmission of language and values from one generation to the next (Dawson, 2012). Children were forced to abandon their language and traditions in cultural isolation (Tapahonso, 2016). Even more surprising and disappointing is how recently this strategy was utilized. Removing children from their families (through a combination of boarding schools and foster placements) in order to eliminate their traditions persisted until the passage of the 1975 Indian SelfDetermination and Education Assistance Act (Tapahonso, 2016, p. 75) and the 1978 adoption of the Indian Child Welfare Act (Sue \& Sue, 2013, p. 384). Tapahonso (2016) points out that even with the passage of these legislative bills, boarding schools persisted into the 1980s, with the 1990 s finally marking the period when the few remaining tribal schools became a place where native culture is taught under community and tribal guidance instead of eliminated through federal intervention (p. 75).

There is also a poorly acknowledged history of willingness to use science as a tool against members of minority groups or to unethically practice science on members of minority groups. The Tuskegee Experiments, which ran from 1932 until 1972, involved the intentional lack of treatment for African American men with syphilis (who were given placebos under the guise of active treatment) to observe the progression of the disease (Sue \& Sue, 2013, p. 90). Beyond the Tuskegee experiments, the eugenics movement in the United States was a social and political movement in private and government sectors that advocated forced contraception for those who were seen as less beneficial to society. Eugenic limitation of reproduction was directed at those with physical, intellectual, and psychological disabilities, but it was also directed at non-European Americans based on the belief that intelligence and personality were genetically distinct across racial groups with some racial groups being superior (and more desirable) in comparison to others (Allen, 2013; Bayor, 2011; Ellis \& Abrams, 2009, p. 388-395; Leonard, 2005). While

EDWARDS / DOI: 10.5929/2017.7.1.3 
the full implementation of eugenics in Germany served as a wake-up call that ended the formal movement in the United States, echoes of eugenics can still be heard in calls for reproductive limitations connected to social services and reactions to immigration and population shifts (Bayor, 2011, p. 60-61).

This represents an extremely incomplete list of racial and ethnic bias and discrimination in U.S. history. It also does not address similar challenges related to religion, sex/gender, sexuality, and disability. However, none of the events described above are ancient history. Japanese internment, Indian boarding schools, the Tuskegee Experiment, and the U.S. Eugenics movement are all recent enough that not only the grandchildren and children of those affected live among us, but those with direct experience are still alive to bear witness. When members of oppressed groups are told that prejudice, intolerance, and discrimination are a thing of the distant past, personal and family history say otherwise.

\section{Recent \& Current Context}

Our challenges in dealing with our own diversity continue as our historical struggles are either mirrored or repeated in current issues and national headlines. Equality related to sex and gender was a focal point of the 2016 election and its aftermath (Stolle, 2017). Rights related to sexuality and gender identity are hotly debated at the local, state, and national level (Duvall, 2017). Prejudice based on ethnicity and religion dominate the discussion of immigration bans as the refugee debate of 2015-2016 (Fernandez, 2016) has morphed into the travel ban battles of 2016-2017 (Richer, 2017), with echoes of Japanese internment (O'Connor, 2017). Racial discrimination and perceptions of it are highlighted by, but in no means limited to, the Black Lives Matter movement and the various reactions against it (Ross \& Lowery, 2017). Even a plan for a cross-national World Cup in North America in 2026 that would be shared between the United States, Canada, and Mexico has required discussions of U.S. policy related to diversity because of the possibility that President Trump's travel bans would impact teams that qualified for matches in the U.S. (Smith, 2017).

As a nation, we spent eight years debating what the election of Barack Obama meant from a race relations perspective (Editorial Board, 2017; Welch \& Sigelman, 2011). We are now debating what the candidacy, nomination, and election of Donald Trump means from a race relations perspective (Douglas \& Harrell, 2017; Savransky, 2017). Arguments that race no longer matters have never been convincing, and now it is an argument that few could seriously support. The most obvious conclusion at this point is that the U.S. has not reached a point where prejudice, discrimination, and racism are a thing of the past.

\section{Growing Interest}

Not only are issues related to our challenges in dealing with diversity current, but literature searches show an increase in both peer reviewed and popular press attention to issues of diversity and discrimination (see Table 1). I used three search terms, "White privilege," "institutional racism," and "microaggression" in selected databases in EBSCOhost, using a search date-range of 2001 to 2017. What emerged clearly suggests that the ideas of race and discrimination have a growing place is our cultural consciousness and discourse.

EDWARDS / DOI: 10.5929/2017.7.1.3 
Table 1

Number of Search Results for Terms Related to Diversity as of May 23, 2017

\begin{tabular}{|c|c|c|c|c|c|c|c|}
\hline & \multicolumn{2}{|c|}{ White Privilege } & \multicolumn{2}{|c|}{ Institutional Racism } & \multicolumn{2}{|c|}{ Microaggression } & \\
\hline & Academic & Popular & Academic & Popular & Academic & Popular & range \\
\hline $\begin{array}{l}2001- \\
2010\end{array}$ & $\begin{array}{c}278 \\
(27.8)\end{array}$ & $\begin{array}{l}60 \\
(6)\end{array}$ & $\begin{array}{l}220 \\
(22)\end{array}$ & $\begin{array}{c}311 \\
(31.1)\end{array}$ & $\begin{array}{c}113 \\
(11.3)\end{array}$ & none & $\begin{array}{c}982 \\
(98.2)\end{array}$ \\
\hline $\begin{array}{l}2011- \\
2015\end{array}$ & $\begin{array}{c}267 \\
(53.40)\end{array}$ & $\begin{array}{c}183 \\
(36.6)\end{array}$ & $\begin{array}{c}121 \\
(22.2)\end{array}$ & $\begin{array}{l}255 \\
(51)\end{array}$ & $\begin{array}{c}406 \\
(81.2)\end{array}$ & $\begin{array}{c}32 \\
(6.4)\end{array}$ & $\begin{array}{c}1264 \\
(252.8)\end{array}$ \\
\hline 2016 & 34 & 178 & 15 & 79 & 129 & 21 & 456 \\
\hline $\begin{array}{l}2017 \\
\text { (through } \\
5 / 23 / 17 \text { ) }\end{array}$ & $\begin{array}{c}5 \\
(12)\end{array}$ & $\begin{array}{c}88 \\
(211.2)\end{array}$ & $\begin{array}{c}3 \\
(7.2)\end{array}$ & $\begin{array}{c}32 \\
(76.8)\end{array}$ & $\begin{array}{c}55 \\
(132)\end{array}$ & $\begin{array}{c}48 \\
(115.2)\end{array}$ & $\begin{array}{c}231 \\
(554.4)\end{array}$ \\
\hline
\end{tabular}

Note. All searches utilized EBSCOhost. Academic searches included PsychINFO, PsychARITICLES, and ERIC. Popular Press searches included Newspaper Source Plus, Newswires, and Web News. Parentheses contain 1 year equivalents for direct comparison with 2016.

While there are limitations to this approach, such as duplicated results, false positives, and false negatives, the searches do demonstrate an increase in interest in White privilege and institutional racism (adjusting for the decreasing amount of time represented in each descending row) in the popular press, with an even larger relative increase in interest in microaggressions, while academic publications on White privilege and institutional racism are decreasing as publications related to microaggressions increase.

Part of the larger increase in microaggression may be due to microaggressions including other demographic divisions beyond race and ethnicity. I believe that this demonstrates further evidence for the relevance and importance of microaggressions as a topic of research and discussion. If the general public and popular press are engaging with this topic, the academic arena should continue to contribute to the discussion.

\section{Institutional Racism \& White Privilege}

In addition to being areas of growing interest in the U.S. social discourse, institutional racism and White privilege are the necessary beginning points for a discussion of microaggressions. A system or institution that directs benefits in one direction while denying those same benefits in other directions is inherently unjust, and any unjust system must lead to unearned privilege (Neville, Worthington, \& Spanierman, 2001, p. 260). 
I would be remiss not to point out that systemic heterosexism leads to heterosexual privilege, systemic gender bias leads to male privilege, systemic ethnocentrism leads to ethnic privilege, and systems that fail to recognize the potential of those with disabilities also confer unjust privilege (Sue \& Sue, 2013). The concepts explored in the following paragraphs are primarily discussed in terms of racial bias and discrimination, but they can, and I would argue should be extrapolated to other forms of bias and discrimination.

Institutional racism is the pervasive pattern of prejudice and discrimination that, in its sum total, limits the most complete access to those in power while placing barriers or unjust requirements of acquiescence on those who are different along lines of race (Sue \& Sue, 2013, p. 123; Utsey, Bolden, \& Brown, 2001, p. 318). Institutional racism differs from the actions of individual racists in significant ways. First, while the stereotypical (individual) racist engages in intentionally aggressive behaviors against those of other racial groups, many of the actions that add up to institutional racism are not intentionally malicious or even consciously directed at those that they negatively impact. Second, the beneficiaries of institutional racism may not be aware of their own benefits or even have any direct contact with those who are being negatively impacted by institutional racism. And, finally, the overall impact of institutional racism is less overtly threatening while being more pervasively damaging (Sue \& Sue, 2013, p. 123-124). For example, when loan policies or the implicit prejudice of a loan officer benefit European American loan applicants, the European Americans who receive better loan rates or more rapid loan approval (and benefit) may never meet the non-European loan applicants who have a more difficult path to home ownership. While the recipients of the privilege may remain unaware, the impact would be widespread and difficult to confront directly.

The strong image of the individual racist in society, as opposed to institutional racism permeating society, complicates our discussions of race and prejudice. Sue and Sue (2013) point out that our usual view of racism committed intentionally by individuals in specific and identifiable situations may hide or distract from the more common institutional or systemic racism that is more harmful to members of minority groups across situations (p. 123). Sue and Sue also recognize that most people do not want to view themselves as racist or prejudiced and suggest that focusing on the overt, individual racist allows most European Americans to dismiss or ignore their own biases and behaviors as non-existent or insignificant in comparison (2013, p. 124).

If some (those who are not perceived as being of European descent) are negatively impacted by institutional racism, then others (those who are perceived as being of European descent) must benefit. This is the most clear and direct form of White privilege (D'Andrea \& Daniels, 2001, p. 261-269). There is, however, a second component of White privilege that is less obvious but more central to the arguments of this article. White privilege includes the ability to ignore institutional racism and insist that White privilege itself does not exist. Being able to ignore, dismiss, or truly believe that privilege does not exist comes from being the recipient of that privilege (Sue et al., 2008). Those who are negatively impacted by institutional racism are less able simply to go through life believing that everything is fair (D'Andrea \& Daniels, 2001, p. 273-274).

EDWARDS / DOI: 10.5929/2017.7.1.3 
White privilege and the background of institutional racism in which White privilege is inherently embedded along with the prejudice upon which they are based are often expressed, transmitted, perpetuated, and maintained in subtle ways. These subtle expressions of racism and privilege are referred to as microaggressions (Sue et al., 2007; Sue et al., 2008; Sue \& Sue, 2013).

\section{Microaggressions}

Sue et al. (2007) defined microaggressions as "brief and commonplace daily verbal, behavioral, and environmental indignities, whether intentional or unintentional, that communicate hostile, derogatory, or negative racial slights and insults to the target person or group" (p. 273). Sue and Sue (2013) expanded on this definition by explicitly including sexism and heterosexism as sources of microaggressions. Sue et al. (2007) also pointed out that microaggressions can be communicated through behavior or environmental conditions. Sue et al. (2008) along with Sue and Sue (2013) continued the exploration of microaggressions by focusing specifically on the confusion that may come with experiencing a microaggression ("what was my experience"), the lack of conscious intent that may accompany microaggression ("that isn't what I meant"), the cumulative impact of microaggressions to those consistently on the receiving end, and, significantly, the ability of perpetrators of microaggressions to deny the existence of microaggressions.

Sue and Sue (2013) provided an extensive list (Table 6.1 of Sue \& Sue) with 16 themes of microaggressions that provides specific examples of types microaggressions along with the subtle (or not so subtle) message transmitted (pp. 156-160). Specific microaggressions can be questions: “'Where are you from?'” (p. 156); compliments: "You are a credit to your race'" (p. 156); and behaviors: "Someone helps you onto a bus or train, even when you need no help" (p. 159). All of them imply that a person's experiences, behaviors, abilities, or values are unusual or deviant and are not valued or welcomed. A briefer, previous version of this table may be found in Sue et al.'s 2007 article (pp. 276-277).

Not all microaggressions are necessarily equal in intent or impact. Sue et al. (2007) divided microaggressions into three subcategories. Microinsults are typically unconscious microaggressions that are "rude, insensitive, or demeaning." Microassaults are more often conscious "explicit racial derogations" that are "meant to hurt the intended victim." Finally, microinvalidations are typically unconscious and "exclude, negate, or nullify the psychological thoughts, feelings, or experiential reality of a person of color" (Figure 1, p. 278).

As Sue and his coauthors (Sue et al., 2007; Sue et al., 2008; Sue \& Sue 2013) pointed out, the subtle nature of each individual microaggression often leads to a dismissal of microaggressions as nonexistent or the resignation of microaggressions to cases of miscommunication and overreaction. The effect of these dismissals is an inability to address the powerful cumulative impact that the microaggressions have across the total experience of those subjected to continuous subtle attacks.

EDWARDS / DOI: 10.5929/2017.7.1.3 
Those in power denying the existence of their own prejudice and invalidating the experiences of those who experience microaggressions may be the result of CoBRAs or Color-Blind Racial Ideology (Kohatsu et al., 2011; Neville et al., 2000; Neville et al., 2013; Zou \& Dickter, 2013).

\section{CoBRAs}

Within multicultural psychology, and multicultural education in general, there is extensive writing on the idea of just ignoring prejudice so that it will go away. One of the main areas for this research is the concept of CoBRAs, which are the values expressed by those who claim to see all people as the same without acknowledging, or even noticing, racial identity (Kohatsu et al., 2011; Neville et al., 2000; Neville et al., 2013; Zou \& Dickter, 2013).

Human experience can be viewed on three levels (Sue \& Sue, 2003, p. 10-14). The Universal Level contains those similar experiences and attributes which all humans share, the Group Level includes similarities (and differences) based on the different groups (including, but not limited to, race, ethnicity, gender, \& sexual orientation) to which we belong, and the Individual Level contains our uniqueness that we share with no one. Color blindness and denial of cultural impacts on experience (including prejudice, discrimination, and oppression) occur when the universal level and the individual level are used as arguments to negate or ignore the group level. This means that when we "only see people," we are using the universal level to avoid the group level (including race), while pointing out that "we are all different" is using the individual level to justify color-blindness (Sue \& Sue, 2007, p. 14-15).

Sue and Sue (2013) included Color Blindness as a specific theme of microaggression: "When I look at you, I don't see color.' 'America is a Melting Pot.' 'There is only one race, the human race.' (p. 157)" that either denies race, denies experience, or demands acculturation. Sue et al. (2007) classified color blindness as an often unconscious microaggression of the microinvalidation variety (Figure 1, p. 278). Therefore, CoBRAs are simultaneously a type of microaggression when acted upon and a passive reason that other microaggressions may go unchallenged, unacknowledged, or unnoticed.

CoBRAs are most likely to be endorsed by those of the majority culture from a racial perspective (Neville et al., 2013). Claiming not to notice racial differences is virtually impossible if you are among those being subjected to differential treatment based on race. CoBRAs present challenges that are directly related to microaggressions and systemic racism. According to Neville et al. (2013) when a color-blind racial ideology is adopted by members of racial minority groups, the result is internalized racism and self-blame for experiences of discrimination. However, when European Americans adopt CoBRAs, the result is colorevasion and power evasion. By refusing to acknowledge color or privilege, European Americans can reduce guilt while experiencing antagonistic attitudes toward members of racial and ethnic minority groups by blaming them for the continued discussion of race. These challenges, contrary to the expressed beliefs of those who endorse CoBRAs, make resolution of prejudice in our society more difficult.

CoBRAs can also contribute to a lack of trust between those of different cultural backgrounds (Arredondo \& Abdullah, 2017). Those who express CoBRAs probably believe that they are demonstrating a more highly

EDWARDS / DOI: 10.5929/2017.7.1.3 
developed view of race and a more embracing approach to diversity (Neville et al., 2013). The opposite is true. Those who endorse CoBRAs tend to have a lower awareness of and value for issues related to diversity (Burkard \& Knox, 2004; Neville et al., 2000; Neville et al, 2013; Wang, Castro, \& Cunningham, 2014). Working from a social psychology perspective, Richeson and Nussbaum (2004) found that those who utilized a color-blind approach (in contrast to a multicultural approach) demonstrated more racial bias.

How can we accept each other if we refuse to see each other? How can we truly accept someone if we refuse to acknowledge different values, experiences, and traditions that are part of their identity? Those who espouse CoBRAs are telling those of different racial identities that they are expected to pretend that we are all the same to avoid the discomfort of admitting that we are different (Sue \& Sue, 2013, p. 157). Instead of representing higher development and advanced acceptance, CoBRAs are perceived by members of racial and ethnic minority groups as a lack of authenticity and openness to any real connection.

Finally, CoBRAs are obstacles to addressing existing prejudice and discrimination from others. If a manager, supervisor, administrator, or educator claims not to see differences based on race, then how can that authority figure recognize or acknowledge when an employee, supervisee, colleague, or student is being discriminated against due to race or is being subjected to microaggressions (Atwater, 2008; Burkard \& Knox, 2004; Offermann et al., 2014; Wang, Castro, \& Cunningham, 2014). If a person cannot acknowledge that race impacts experience, then the negative impacts of prejudice cannot be addressed.

Our basic communication patterns and reactions to others have been linked to CoBRAs. Zou and Dikter (2013) found that CoBRAs predicted how European Americans would respond to ambiguous racially charged comments; those with higher levels of color-blindness were more likely to believe that people were overreacting to comments with subtle racial insults. Tynes and Markoe (2010) examined interactions on social networks. They found that participants with higher CoBRA levels were less likely to recognize offensive racial material in social network posts and that higher CoBRA levels predicted a lower likelihood of confronting racist content when it was recognized.

More situation-specific research related to CoBRAs has been conducted across disciplines. The effects of CoBRAs held by counselors (Burkard \& Knox, 2004; Neville et al., 2001; Sue et al., 2007; Sue \& Sue, 2013), teachers (Atwater, 2008; Wang, Castro, \& Cunningham, 2014), college students (Neville et al., 2014; Neville et al., 2011; Poteat \& Spanierman, 2012; Worthington et al., 2008), and managers (Offerman et al., 2014) have been explored.

Burkard and Knox (2004) found that therapists who demonstrated high levels of CoBRAs were lower on empathy for all clients, had a lower awareness of cultural challenges, and were more likely to assign responsibility for solutions to problems to African American clients than to European American clients. Sue et al. (2007) described multiple ways that CoBRAs may lead to less trust and a less helpful therapeutic relationship, including blaming clients for their problems, dismissing possible cases of discrimination, and minimizing the experiences of those who are from racial or ethnic minority groups (p. 280-281). Also, Sue

EDWARDS / DOI: 10.5929/2017.7.1.3 
and Sue (2013) explained how Color Blindness can lead to blaming clients (p. 119), denying experience with a demand for acculturation (p. 157), and believing that race is not an important part of experience (p. 170).

In arguing that race still matters in schools and in teacher training, Atwater (2008) connected previous research to suggest that observed differences in teacher opinions of students (race predicts level of intelligence or potential) and approaches to teaching (especially attempting to change the values of ethnic minority students) could be related to color-blind approaches of teachers promoted by teacher education and school policy. Also, Wang, Castro, and Cunningham (2014) found that color blindness could help explain relationships between other variables (such as perfectionism and individualism) and cultural diversity awareness. In short, their study demonstrated that CoBRAs could help explain why some teachers have less cultural sensitivity when working with students from racial and ethnic minority groups.

How college students view and react to campus climate and events is also influenced by CoBRAs. Lewis, Neville, and Spanierman (2012) found that higher levels of color-blindness predicted lower levels of social justice attitudes. Additionally, Poteat and Spanierman (2012) found that color-blind racial ideology predicted higher levels of racist ideology and interacted with other predictors of racial bias. Worthington et al. (2008) demonstrated that higher levels of color-blindness predicted a more positive rating of general campus climate, suggesting that those who endorse CoBRAs at a higher level will be less likely to recognize hostile environments when they exist. Specifically, Neville et al. (2011) found that lower levels of CoBRAs predicted more support for discontinuing the use of a racialized (American Indian) university mascot while higher CoBRA scores predicted a negative reaction to the decision and general support for the use of a stereotyped college mascot.

Poteat and Spanierman (2012) recommended explicitly addressing CoBRAs among college students as a way of decreasing racist attitudes (p. 770). Lewis, Neville, and Spanierman (2012) found that campus diversity experiences did predict changes in social justice attitudes and a decrease in color-blind racial ideology. Adding further credibility to Poteat and Sapneriman's (2012) recommendation, Neville et al. (2014) reported on a longitudinal study of college students and CoBRAs that demonstrated a general decrease in CoBRAs as time in college increased and that the decrease in CoBRAs was greater for students who enrolled in courses specifically addressing diversity.

Offerman et al. (2014) examined the connection between color-blindness and discrimination in the workplace. In addition to finding that European Americans in the workplace were more likely to endorse CoBRAs (p. 504), they found that CoBRAs predicted a lower perception of microaggressions and institutional discrimination. As suggested above, managers with higher levels of CoBRAs seem less likely to recognize discrimination in their organizations, and are, therefore, less likely to be able to support employees who are experiencing discrimination.

EDWARDS / DOI: 10.5929/2017.7.1.3 


\section{Conclusion}

CoBRAs apply directly to prejudice and discrimination based on race by being both product of institutional racism and White privilege and a perpetuating factor in them. A parallel process can apply to gender, sexual orientation, ethnicity, religion, disability, and other cultural factors. If we refuse to embrace our differences, then we cannot truly accept each other. If we can't see difference in experience, then we will never be able to fully understand when that difference includes prejudice, discrimination, and oppression.

However, when we choose to truly explore our differences and really see others with their identities and experiences intact, then we can move toward true acceptance and valuation of diversity. Open exploration and recognition is part of the solution, not the source of our problems. Recently a student asked me if openly discussing differences quit being awkward. From my experience, I had to say no, but that seeing that it does make a positive difference makes it easier to push yourself into that awkward but important area.

The articles contained in this issue of the AlJ come from different perspectives and address different types of microaggressions, including but not limited to microaggressions based on race and ethnicity. The topics presented may not be comfortable, but for true progress these conversations are an important step. As Poteat and Spanierman (2012), Lewis, Neville, and Spanierman (2012), and Neville et al. (2014) found, exposure helps us move past color-blindness and toward a more authentic acceptance.

References

Allen, G. E. (2013). "Culling the Herd"; Eugenics and the conservation movement in the United States, 1900-1940. Journal of the History of Biology, 46, 31-72. doi: 10.1007/s10739-011-9317-1

Allerfeldt, K. (2003). Race and restriction: Anti-Asian immigration pressures in the Pacific North-west of America during the progressive era, 1885-1924. History, 88, 53-73.

Arredondo, P., \& Abdullah, L. B. (2017). Organizational change in institutions of higher education. In J. M. Casas, L. A. Suzuki, C. M. Alexander, \& M. A. Jackson (eds.) Handbook of Multicultural Counseling ( $4^{\text {th }}$ ed.) (pp. 485-498). Thousand Oaks, CA: Sage.

Atwater, S. A. C. (2008). Waking up to difference: Teachers, color-blindness, and the effects on students of color. Journal of Instructional Psychology, 35, 246-253.

Bayor, R. H. (2011). The development and impact of "science"; The role of eugenics. Journal of American Ethnic History, 30, 58-61.

Burkard, A. W., \& Knox, S. (2004). Effect of therapist color-blindness on empath and attributions in crosscultural counseling. Journal of Counseling Psychology, 51, 387-397. doi: 10.1037/00220167.51.4.387

Calavita, K. (2006). Collisions at the intersection of gender, race, and class: Enforcing the Chinese exclusion laws. Law \& Society Review, 40, 249-281.

EDWARDS / DOI: 10.5929/2017.7.1.3 
D’Andrea, M., \& Daniels, J. (2001). Expanding our thinking about White racism: Facing the challenge of multicultural counseling in the $21^{\text {st }}$ century. In J. G. Ponterotto, J. M. Casas, L. A. Suzuki, \& C. M. Alexander (eds.) Handbook of Multicultural Counseling ( $2^{\text {nd }}$ ed.) (pp. 289-310). Thousand Oaks, CA: Sage.

Dawson, A. S. (2012). Histories and memories of the Indian boarding schools in Mexico, Canada, and the United States. Latin American Perspectives, 39, 80-99.

Douglas, W. \& Harrell, D. (2017, March 6). Blacks, Whites, and Latinos agree: Race relations are getting worse under Trump. Bellingham Herald. Bellingham, WA.

Duvall, E. (2017, May 18). U.S. remains split on need for LGBT anti-discrimination laws Dec. 31 (UPI). UPI Top News.

Editorial Board. (2017, January 16). A King Day like no other; Obama's last as president. The Philadelphia Inquirer. Philadelphia, PA.

Ellis, A., \& Abrams, M. (2009). Personality Theories: Critical Perspectives. Thousand Oaks, CA: Sage.

Faragher, J. M., Buhle, M. J., Czitrom, D., \& Armitage, S. H. (2012). Out of Many: A History of the American People $\left(6^{\text {th }}\right.$ ed.) Upper Saddle River, NJ: Prentice.

Fernandez, M. (2016, September 22). Texas threatens to leave federal refugee resettlement program. The New York Times. New York, NY.

Kohatsu, E. L., Victoria, R., Lau, A., Flores, M., \& Salazar, A. (2011). Analyzing anti-Asian prejudice from a racial identity and color-blind perspective. Journal of Counseling \& Development, 89, 63-89.

Leonard, T. C. (2005). Mistaking eugenics for Social Darwinism: Why eugenics is missing from the history of American economics. History of Political Economy, 37, 200-233.

Lewis, J. A., Neville, H. A., \& Spanierman, L. B. (2012). Examining the influence of campus diversity experiences and color-blind racial ideology on students' social justice attitudes. Journal of Student Affairs Research and Practice, 49, 119-136. doi: 10.1515/jsarp-2012-6291

Muyskens, J., \& Steckelberg, A. (2017, February 19). Incarceration by executive order: Remembering Japanese American internment camps, 75 years later. The Washington Post. Washington, DC.

Neville, H. A., Awad, G. H., Brooks, J. E., Flores, M. P., \& Bluemel, J. (2013). Color-blind racial ideology: Theory, training, and measurement implications in psychology. American Psychologist, 66, 455466. doi: $10.1037 / \mathrm{a} 0033282$

Neville, H. A., Lilly, R. L., Duran, G., Lee, R. M., \& Browne, L. (2000). Construction and initial validation of the Color-Blind Racial Attitudes Scale (CoBRAS). Journal of Counseling Psychology, 47, 59-70. doi: 10.1037//0022-0167.47.1.59

Neville, H. A., Poteat, V. P., Lewis, J. A., Spanierman, L. B. (2014). Changes in White college students' colorblind racial ideology over 4 years: Do diversity experiences make a difference? Journal of Counseling Psychology, 61, 179-190. doi: 10.1037/a0035168 
Neville, H. A., Worthington, R. L., \& Spanierman, L. B. (2001). Race, power, and multicultural counseling psychology: Understanding White privilege and color-blind racial attitudes. In J. G. Ponterotto, J. M. Casas, L. A. Suzuki, \& C. M. Alexander (eds.) Handbook of Multicultural Counseling ( $2^{\text {nd }} e d$.) (pp. 257-288). Thousand Oaks, CA: Sage.

Neville, H. A., Yeung, J. G., Todd, N. R., Spanierman, L. B., \& Reed, T. D. (2011). Color-blind racial ideology and beliefs about a racialized university mascot university mascot. Journal of Diversity in Higher Education, 4, 236-249. doi: 10.1037/a0024334

O'Connor, T. (2017, February 19). Japanese internment anniversary: What happened and why Trump's travel ban angers civil rights groups 75 years later. International Business Times. http://www.ibtimes.com/japanese-internment-anniversary-what-happened-why-trumps-travelban-angers-civil-2492747

Offermann, L. R., Basford, T. E., Graebner, R., Jaffer, S., Graaf, S. B. D., \& Kaminsky, S. E. (2014). See no evil: Color blindness and perceptions of subtle racial discrimination in the workplace. Cultural Diversity and Ethnic Minority Psychology, 20, 499-507. doi: 10.1037/a0037237

Poteat, V. P., \& Spanierman, L. B. (2012). Modern racism attitudes among White students: The role of dominance and authoritarianism and the mediating effects of racial color-blindness. The Journal of Social Psychology, 152, 758-774.

Richer, A. D. (2017, May 8). Appeals court hears arguments on Trump's revised travel ban. The Associated Press.

Richeson, J. A., \& Nussbaum, R. J. (2004). The impact of multiculturalism versus color-blindness on racial bias. Journal of Experimental Social Psychology, 40, 417-423. doi: 10.1016/j.jesp.2003.09.002

Ross, J., \& Lowery, W. (2017, May 8). Facing Trump, Black Lives Matter switches to policy battles. The Washington Post. Washington, DC.

Savransky, R. (2017, March 13). Poll: Majority thinks race relations will deteriorate under Trump. The Hill. Washington, DC.

Smith, R. (2017, February 27). U.S. is warned travel bans would harm World Cup bid. The New York Times (Late Edition). New York, NY.

Stefanoni, A. B. (2015, February 21). Debate could change course of history classes. The Joplin Globe. Joplin, MO.

Stolle, M. (2017, January 23). What does it mean to be feminist now? Post-Bulletin. Rochester, MN.

Sue, D. W., Capodilupo, C. M., Nadal, K. L., \& Torino, G. C. (2008). Racial microaggressions and the power to define reality. American Psychologist, 63, 277-279. doi: 10.1037/0003-66x.63.4.277

Sue, D. W., Capodilupo, C. M., Torino, G. C., Bucceri, J. M., Holder, A. M. B., Nadal, K. L., \& Esquilin, M. (2007). Racial microaggressions in everyday life: Implications for clinical practice. American Psychologist, 62, 271-286. doi: 10.1037/0003066x.62.4.271

EDWARDS / DOI: 10.5929/2017.7.1.3 
Sue, D. W., \& Sue, D. (2003). Counseling the Culturally Diverse: Theory and Practice ( $4^{\text {th }}$ ed.). Hoboken, NJ: Wiley.

Sue, D. W., \& Sue, D. (2013). Counseling the Culturally Diverse: Theory and Practice ( $6^{\text {th }}$ ed.). Hoboken, NJ: Wiley.

Tapahonso, L. (2016). Two nations. Smithsonian, 47, 68-75.

Tynes, B. M., \& Markoe, S. L. (2010). The role of color-blind racial attitudes in reactions to racial discrimination on social network sites. Journal of Diversity in Higher Education, 3, 1-13. doi: $10.1037 / \mathrm{a} 0018683$

Utsey, S. O., Bolden, M. A., \& Brown, A. L. (2001). Visions of revolution from the spirit of Frantz Fanon: A psychology of liberation for counseling African American confronting societal racism and oppression. In J. G. Ponterotto, J. M. Casas, L. A. Suzuki, \& C. M. Alexander (eds.) Handbook of Multicultural Counseling ( $2^{\text {nd }}$ ed.) (pp. 311-336). Thousand Oaks, CA: Sage.

Wang, K. T., Castro, A. J., \& Cunningham, Y. L. (2014). Are perfectionism, individualism, and racial colorblindness associated with less cultural sensitivity? Exploring diversity awareness in White prospective teachers. Journal of Diversity in Higher Education, 7, 211-225. doi: 10.1037/a0037337

Welch, S., \& Sigelman, L. (2011). The "Obama Effect" and White racial attitudes. The Annals of the American Academy of Political and Social Science, 634, 207-220. doi: 10.1177/0002716210386302

Wollenberg, C. (2012). "Dear Earl" The Fair Play Committee, Earl Warren, and Japanese internment. California History, 89, 24-55.

Worthington, R. L., Navarro, R. L., Loewy, M., \& Hart, J. (2008). Color-blind racial attitudes, social dominance orientation, racial-ethnic group membership and college students' perceptions of campus climate. Journal of Diversity in Higher Education, 1, 8-19. doi: 10.1037/1938-8926.1.1.8

Zou, L. X., \& Dickter, C. L. (2013). Perceptions of racial confrontation: The role of color-blindness and comment ambiguity. Cultural Diversity and Ethnic Minority Psychology, 19, 92-96. doi: $10.1037 / \mathrm{a} 0031115$

\section{About the Author}

Jared F. Edwards, Ph.D. (Jared.edwards@swosu.edu) is a tenured Associate Professor of Psychology at Southwestern Oklahoma State University, with a Ph.D. and M.A. in Psychology, specializing in Counseling Psychology from Southern Illinois University-Carbondale along with a B.S. in Psychology from Southeast Missouri State University at Cape Girardeau. Dr. Edwards' pre-doctoral internship was at the University Counseling Center-University of Utah. His sub-specialization is Vocational Psychology, with both thesis and dissertation focused on career development. Research areas include Teaching of Psychology, Multicultural Psychology/Diversity in Education, and Career Development and Social Cognitive Career Theory. Dr. Edwards has helped to facilitate over 20 student-led presentations at regional conferences, helping students gain experience in research, data analysis, and professional communication.

EDWARDS / DOI: 10.5929/2017.7.1.3 